\title{
Urgency of migrant health policy in Nepal
}

\section{Opinion}

Mr Chandraman Tharu, aged 84yrs, an inhabitant of Western Nepal was seated cross legs with tearing eyes on the floor near a red wooden Box in Trivubhan International Airport as he received death body of his son from Malaysia. In the same day, a 19 year's lactating mother with her two months baby was also in disconsolate and waiting for her husband corpse from Saudi Arabia. Nowadays, these stories are not uncommon in families of the Nepalese migrant worker. Among 2000 peoples seeking work permission present day to go aboard, all most three dead bodies of Nepalese migrant worker are returning every day from foreign land. According to the foreign employment promotion board, in 2015, Nepal lost 1002 young bloody workers in different countries except that of India. Thousands of labors became sick and many of them are markedly depressed. Reports from central mental hospital of Nepal showed most of the depressed patients are those who returned from foreign land. Formal and informal estimate suggests nearly $15 \%$ of the total population is currently working aboard which is the almost five folds greater than the global average. There are an estimated 5.5 million Nepali migrant workers in Far East, Middle East, Golf, India and even in Africa. Rural village across the country are empty of working age men i.e. mostly the elderly, the disabled, children and women left behind. Nowadays, it is commonly said in Nepalese probe that rural village of Nepal are only the place of youth less and toothless. Due to the disruption of economic activities by the recent earthquake and six month economic blockade by India, the migrant outflow will certainly increase for some years. Official data, from ministry of labor and employment further reveal that out of half a million youths entering the labor market each year, only 50,000 get gainful employment opportunities at home. ${ }^{1-4}$

In one hand, remittance becoming the life-line of the country's economy but the health of migrants and health matters associated with migration are crucial public health challenges faced by government of Nepal. Various health issues not only related to the migrant worker but also the family members who are left behind in home country largely go unnoticed. Along with the pre-existing infectious diseases, the other domain of health for example mortality, behavioral risk and genetic problem are also some issues being faced by Nepal today. The data from Central Bureau of Foreign Labor, Nepal shows renal failure, severe cardiac diseases, road traffic accidents, sexually transmitted infection; suicidal cases as well as mental and psychosocial health issue are generating greater attention. Subjective evidence has suggested that the reason for the high mortality rates of Nepalese workers is because of excessive intake of homemade alcohol and the risky nature of many jobs. The most recent study about Nepalese migrants in the Middle East has found that many Nepalese have been working in risky occupations and 3D's job(danger ,difficult and dirty) because $90 \%$ of them are unskilled and about one in four migrants face accidents and injuries during their work. Likewise, very few migrants have been provided with safety training and most of them do not have private health insurance. One of the studies from International Organization of Migration (IOM) showed the life associate death-issues like tobacco use, alcohol consumption and

\author{
Volume 4 Issue 6 - 2016
}

\author{
Gokarna Dahal \\ Department of Global Health and Development, Hanyang, seoul \\ korea
}

Correspondence: Gokarna Dahal, Department of Global Health and Development, Hanyang, seoul korea, Tel +977082693222, Email dahalgokarna7@gmail.com

Received: August 12, 2016 | Published: September 02, 2016

substances abuse in migrant worker are also the increasing headache for government of Nepal. Of the total number of Nepali migrants, between $3.4 \%$ and $10 \%$ are estimated to be women. It is estimated that 5,000-15,000 Nepali women are victims of human trafficking each year through irregular and unlawful channel primarily to India and the Middle East. Referring to the previous data, among all the prevalence of HIV infection in Nepal, $27 \%$ are in among migrant labor and expected to raise with the increase in the mobility of migrant worker. This remittance policy not only affecting the migrant worker health but the health of those family members who are left behind are also in crisis. Emotional distresses like sadness, poor sleep, obsessive thinking, loneliness, crying are associated with the losing their own family member. This emotional pain is not something like a fever or backache which can be easily discussed with family or easily treated with magic pills .Not only emotional component is affected; they also have poorer physical and mental health components.

Of course, migrant workers' contribution to our economy and society has become increasingly enormous. Remittance in Nepal is becoming the new life line and is the third largest recipients of remittances in the world relative to the size of its economy(nearly one third of its GDP).The amount is about seven billion dollars annually and is comparable with our annual budget and trade deficit. Estimates also suggest that 60-70 per cent of our households send their members abroad for work. The latest Nepal Living Standard Survey has claimed that remittances have been the most prominent factor behind the significant reduction in absolute poverty in the country. But recent research revealed that influx of remittance is not eliminating the poverty but creating the new kinds of poor by deteriorating the health of migrant labor in Nepal. It is also distracting the policy changes leading to great social problem and disharmony in society.

Nepal is the member country and has approved various human rights conventions and International Labor Organization conventions related to migration. However, Nepal has still not signed the petitions for two major conventions related to migration: Convention on the Protection of the Rights of All Migrant Workers and Members of Their 
Families, and UN Protocol to Prevent, Suppress and Punish Trafficking in Persons. Furthermore, there are no policies or guidelines for the reintegration of Nepalese migrants, including those deemed unfit and deported by their receiving country. There are several serious cases of the situation of Nepalese migrants working in unauthorized countries without any legal or social protection by the host countries.

Health issue of migrant worker should be an essential and nonnegotiable component when Nepal establishes bilateral labor agreements with any labor receiving country. The government of Nepal should create effective health related foreign policies, especially at the diplomatic level so that all high level diplomats show concern and take necessary action if any Nepali citizen faces problems related to his/her life and health risks.

\section{Acknowledgements}

None.

\section{Conflict of interest}

The author declares no conflict of interest.

\section{References}

1. Sevoyan A, Agadjanian V. Male migration, women left behind, and sexually transmitted diseases in Armenia. International Migration Review. 2010;44(2):354-375.

2. Migration Health. Annual Review, IOM; 2014.

3. Migration and Health. HERD international; 2016.

4. Health vulnerabilities of migrant from Nepal. Baseline assessment IOM and HERD. 2015. 